Www.jmscr.igmpublication.org

Impact Factor 5.84

Index Copernicus Value: 83.27

ISSN (e)-2347-176x ISSN (p) 2455-0450

crossref DOI: _https://dx.doi.org/10.18535/jmscr/v5i7.220

Journal Of Medical Science And Clinical Research

\title{
A study on clinical profile of extra hepatic manifestation of Hepatitis C infection
}

\author{
Authors \\ Suresh Raghavan $\mathrm{MD}^{1}$, Udayamma $\mathrm{KP}^{2}$ \\ ${ }^{1}$ Professor, Department of Medicine, Government T D Medical College, Alappuzha \\ ${ }^{2}$ Associate Professor, Department Of Medicine, Government T D Medical College, Alappuzha \\ Corresponding Author \\ Suresh Raghavan MD \\ Professor, Department of Medicine, Government T D Medical College, Alappuzha
}

\begin{abstract}
Background: Approximately 3\% of the world population is infected with Hepatitis $C$ virus, with the highest prevalence noted in Africa and Asia. In India, the prevalence of Hepatitis $C$ virus infection ranges from $0.3 \%$ to $0.4 \%$ of the general population in different parts of the country, where it accounts for 0 $12.8 \%$ of acute hepatitis, 10-20\% of chronic liver disease and 10-15\% of Hepatocellular Carcinoma. Several extra hepatic manifestations have been reported in hepatitis $C$ infection. According to different studies, $40-74 \%$ of patients infected with the virus develop atleast one of the extrahepatic manifestations during the course of the disease. Extrahepatic manifestations may be the only and the first signal of an $H C V$ infection, as many patients may not show any hepatic symptoms. Hence, detection of extrahepatic manifestation may help in easly diagnosis and initiation of treatment. So this study was undertaken to find out the prevalence and the common extrahepatic manifestations of Hepatitis $C$ infection in a teritiary care centre in south Kerala, Government T D Medical College Alappuzha.

Materials and Methods: This study included a total of 95 patients diagnosed as HCV infected, attending the medical/ Gastroenterology wards/ OPD of the institution. It was a cross sectional study carried out over a period of 1 year regarding the clinical charecteristics of Hepatitis $C$ infected patients.

Results: Extrahepatic Manifestations were seen in around $47.37 \%$ of the total sample population. They included neurological, renal, rheumatological and skin manifestations. Skin manifestations were the commonest. However Essential mixed cryoglobulinemia could not be detected due to the absence of a well set up laboratory facility.

Conclusion: Beyond the liver, HCV is a multifaceted disease. Some of the extrahepatic manifestations are due to immune reaction and some are due to chronic inflammation. Recognition of the extrahepatic manifestation is of paramount importance in early diagnosis of the disease.

Keywords: Hepatitis $C$, extrahepatic manifestations.
\end{abstract}

\section{Background}

Viral Hepatitis is a major global health problem and Hepatitis $C$ virus is 1 of 6 hepatotropic viruses that together account for the majority of cases of viral hepatitis ${ }^{1-4}$. Approximately $3 \%$ of the world population is infected with Hepatitis $\mathrm{C}$ virus, with the highest prevalence in Africa and Asia ${ }^{5}$. This leads to the increased incidence of hepatitis $C$ in healthy as well as diseased population. Hepatitis $\mathrm{C}$ infection contributes $20-40 \%$ of all viral hepatitis 
with highest prevalence of carrier state and more than $70 \%$ of these patients progress to chronic infection with serious complications ${ }^{6}$.

In India, the prevalence of $\mathrm{HCV}$ infection ranges from 0.3 to $4 \%$ in the general population in different parts of the country ${ }^{7}$. In industrialized countries, HCV accounts for $20 \%$ of acute hepatitis, $70 \%$ of chronic hepatitis, $40 \%$ of cirrhosis, $60 \%$ of hepatocellular carcinoma and $30 \%$ of liver transplantation ${ }^{8}$; whereas in India, it is responsible for $0-12.8 \%$ acute hepatitis, $10-20 \%$ of chronic liver disease and $10-15 \%$ of $\mathrm{HCC}^{7,9}$. Vertical, horizontal and sexual transmission has been suggested as potential sources of the transmission of $\mathrm{HCV}^{10}$.

Several extra hepatic manifestations have been reported in the natural history of Hepatitis $\mathrm{C}$ infection $^{11}$. According to different studies, 40$70 \%$ of patient may develop at least one extra hepatic manifestation during the course of the disease $^{12,13}$. Further, extra hepatic manifestations may be the first signal of an HCV infection, as many patients show no hepatic symptoms.

Pascual et al ${ }^{14}$ first described the association between $\mathrm{HCV}$ and extra hepatic manifestation in 1990, reporting two patients with mixed cryoglobulinemia. Subsequently, the involvement of various organs and organ systems (kidney, skin, thyroid, eyes, joints and nervous system) were also reported ${ }^{15}$. The infected extra hepatic tissues might act as the reservoir of $\mathrm{HCV}$ and play a role in both $\mathrm{HCV}$ persistence and reactivation of infection. $\mathrm{HCV}$, as an etiological agent replicating and expressing viral proteins in extra hepatic tissues itself contributes to extra hepatic manifestations associated with chronic $\mathrm{HCV}$ infection.

An important feature of $\mathrm{HCV}$ is that it avoids immune elimination and as a consequence leads to accumulation of circulating immune complexes and autoimmune phenomenon ${ }^{16}$. HCV shows a particular lymph node tropism other than hepatic tropism that is responsible for the extra hepatic manifestations ${ }^{16}$.

Extra hepatic manifestation may be the presenting feature in hepatitis $\mathrm{C}$ infection and may help in early diagnosis and treatment. So this study was designed to know the prevalence and the common extra hepatic manifestations of $\mathrm{HCV}$ in a tertiary care centre in South Kerala, The Government T D Medical College, Alappuzha.

\section{Materials and methods}

The study was conducted in The Government TD Medical College, Alappuzha from the period 2014-2015. It was a hospital based cross sectional study among the HCV positive patients attending the OPD and wards of the Medicine and Gastroenterology Departments of the institution. The sample size was 95. The various clinical parameters were studied among those who satisfied the inclusion criteria.

\section{Inclusion criteria}

1. Subjects who gave consent and were diagnosed as $\mathrm{HCV}$ positive and who are above 18 years of age.

\section{Exclusion Criteria}

1. Patients not giving consent.

2. Patients who are hemodynamically unstable.

3. Patients treated with interferon alpha.

Written consent was obtained from all those who satisfied the inclusion criteria. They were evaluated with a detailed history, physical examination and investigations as per the proforma. The statistical analysis was done using SPSS version 16. All the numerical variables were compared using independent $t$ test or ANOVA. Associations between numerical variables were computed using Pearson's correlation co efficient. Quantitative data were expressed as mean and standard deviation. $\mathrm{P}$ values of $<0.05$ were considered significant.

\section{Results}

Of the 95 subjects, $68.4 \%$ were males and $31.6 \%$ were females, the mean age being 58.6 .

The maximum of $41.05 \%$ of cases were seen in the age group of $61-70$ years. The minimum $(5.26 \%)$ was seen in the age group of 31-40 years 


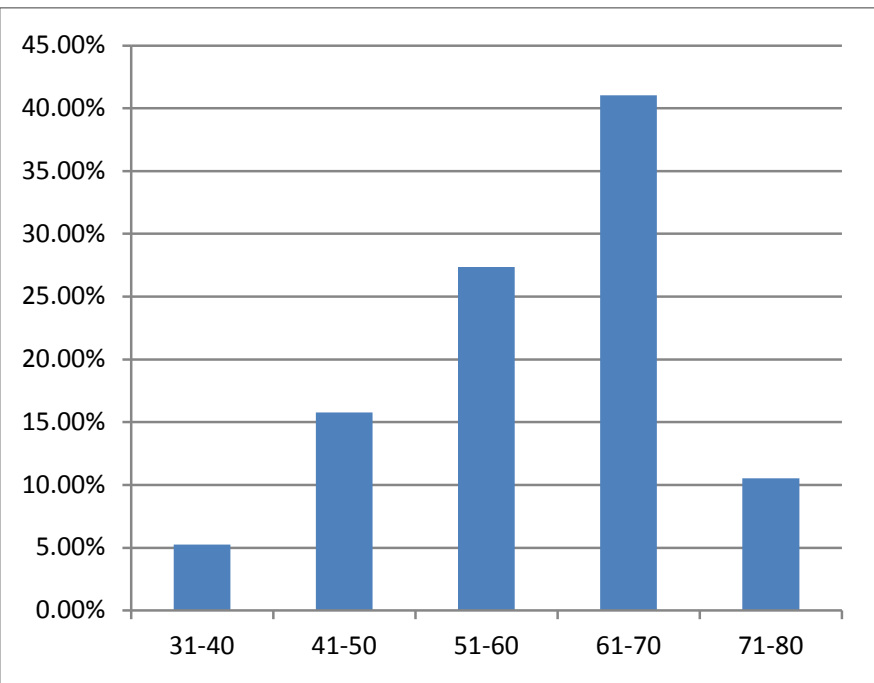

Distribution of sample according to age

Extra hepatic manifestations were seen in $47.4 \%$ of the sample.

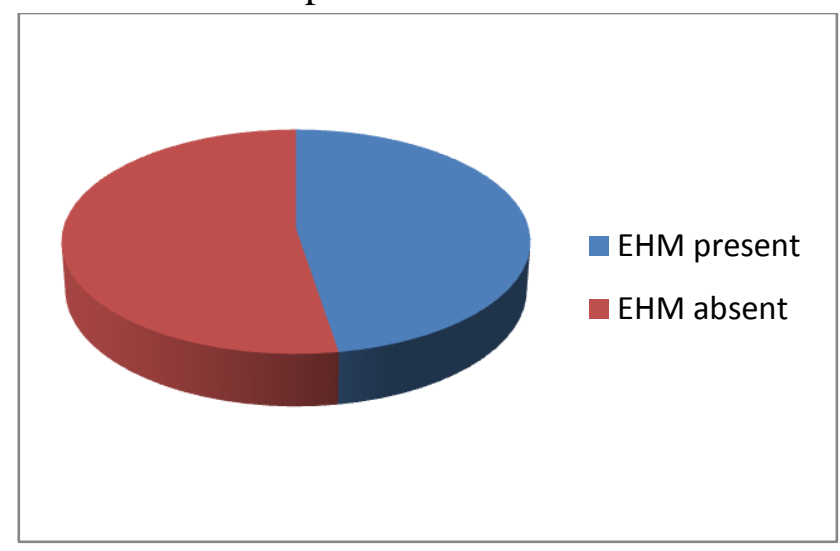

The percentages of extra hepatic manifestations were $30.77 \%$ in males and $83.33 \%$ in females.

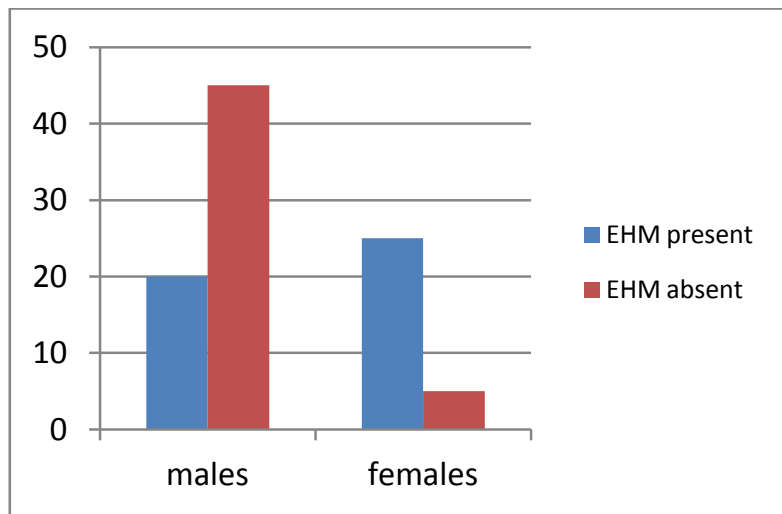

Distribution of sample based on extra hepatic manifestation among both the genders

The most common extra hepatic manifestation was dermatologic, followed by rheumatologic. Neurologic manifestation was seen in 14 patients and the least common was renal manifestation.

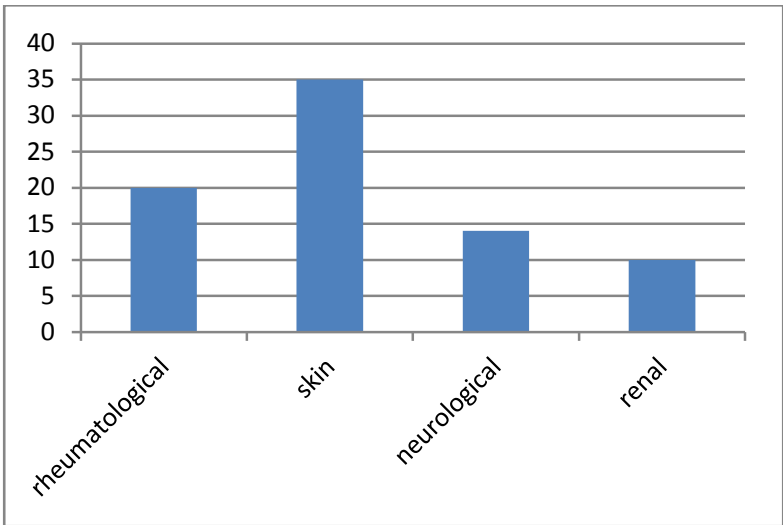

Distribution of sample based on various extra hepatic manifestations.

Rheumatologic manifestation was seen in $33.33 \%$ of the infected females and $15.38 \%$ of the infected males. Rheumatologic manifestations were more seen in the age group of 61-70 years (50\%). Cetaceous manifestations were seen in $66.67 \%$ of the infected females and $25 \%$ of the infected males. The highest number of skin manifestations was also seen in the age group of 61-70 years (36.84\%). Neurological manifestation was more seen in infected males than females $(10.53 \% \mathrm{Vs}$ $4.21 \%$ ). Renal manifestation was equally seen in both males and females (5.26\% each).

\section{Conclusions}

Out of the 95 cases, $68.4 \%$ were males and $31.6 \%$ were females, the mean age being 58.64 years. the extra hepatic manifestations in our study was $47.37 \%$. The various extra hepatic manifestations were neurological, renal, rheumatologic and skin manifestations. Skin manifestations were the commonest in this study seen in $34.84 \%$ of the subjects, followed by rheumatologic in $21.05 \%$, neurological in $14.74 \%$ and least was renal seen in $10.53 \%$ of the subjects.

In most of the studies, the most common extra hepatic manifestation reported was mixed cryoglobulinemia. However for the detection of mixed cryoglobulinemia, a well set up laboratory is required and since this study was only a clinical profile study, the prevalence of cryoglobulins was not determined. It is usually seen in patients with skin and rheumatologic manifestations.

Rheumatologic and skin manifestations were seen more commonly in females than in males. Neurological manifestations had a male 
predominance and renal manifestations were seen equally in males and females.

Skin manifestations included purpurae, vesicles, bullae, lichen planus and porphyria cutanea tarda. Arthritis was the commonest rheumatologic manifestation and sensor motor neuropathy was the neurological manifestation. Renal manifestation was chronic glomerulonephritis.

Extra hepatic manifestations are very common with chronic HCV infection. It should be well recognized by the clinicians and should have an impact on the care of patients with HCV infection.

\section{Acknowledgement}

We thank the Almighty for His unfailing love and bountiful blessings during this research endeavor. We owe a great deal of thanks to the Government TD medical college, Alappuzha for providing us the opportunity to conduct this study. We express the most sincere thanks to all the teaching and non teaching staff of the departments of medicine and gastroenterology of our institution. Last but not the least we great fully remember all the patients who gave consent and participated in this study

\section{References}

1. Waheed, Y., T. Shafi, S.Z. Safi and I. Qadri, 2009. Hepatitis C in Pakistan. A systematic review of prevalence, genotype and risk factors. World J Gastroenterol,15:5647-5653.

2. Wasley, A.D. and M.J. Alter, 2000. Epidemiology of hepatitis C. Semin Liver Dis., 20: 1-16.

3. Shah, N.H. and G. Shabbir, 2002. A review of published literature on hepatits $\mathrm{B}$ and $\mathrm{C}$ virus prevalence in Pakistan. J. Coll Physicians Surg. Pakistan, 12: 368-371.

4. Faridullah, S.M., I.A. Malik and I. HussainI, 2002. Increasing prevalence of chronic hepatitis and associated risk factors. Pakistan J. Med. Research, 41: 46-50.

5. Gretch, D.R., C.E. Bacchi and L. Corey, 1995. Persistent hepatitis C virus infection after liver transplantation: clinical and virological features. Am. J. Hepatol., 22: 1-9.
6. Degos, F., 1996. Natural history of hepatitis C virus infection. Nephrol Dial Transplant, 11(suppl 4): 16

7. Arankalle VA. Epidemiology of $\mathrm{HCV}$ infection in India: a comprehensive analysis. In: Sarin SK, Okuda K eds. Hepatitis B and C- carrier to cancer. Harcourt India Pvt. Ltd. India. 2002;201-

8. Alter MJ. World Epidemiology of Hepatitis C. Hepatitis Annual Update. 2004;77-92.

9. Amarapurkar D. Natural history of hepatitis $\mathrm{C}$ virus infection. J Gastroenterol Hepatol. 2000;15:105-110

10. Simmonds, P., 2001. Fleming Lecture: the origin and evolution of hepatitis viruses in humans. J. Gen. Virol., 82: 693-712.

11. Agnello, V., 2000. Mixed cryoglobulinemia and other extra hepatic manifestations of HCV infection. In: Hepatitis C. Eds., T.J. Liang and J.H. Hoofnagle. New York: Academic Press, pp: 295-315.

12. Cacoub, P., C. Renou and E. Rosenthal, 2000. Extrahepatic manifestations associated with hepatitis $\mathrm{C}$ virus infection. A prospective multicenter study of 321 patients. Group ed'Etude et de Recherche en Medecine Interne et Maladies Infectieuses sur le Virus de l'Hepatite C. Medicine., 79: 47-56.

13. Cacoub, P., T. Poynard and P. Ghillani, 1999. Extrahepatic manifestations of chronic hepatitis C. MULTIVIRC group. Multidepartment Virus C Arthritis Rheum,42:2204-2212

14. Pascual, M., L. Perrin, E. Giostra and J.A. Schifferli, 1990. Hepatitis C virus in patients with cryoglobulinemia type II. J. Infect Dis., 162: 569-570.

15. Ferri, C., M. Monti and L. La Civita, 1993. Infection on peripheral blood momonuclear cells by hepatitis $\mathrm{C}$ virus in mixed cryoglobulinemia. Blood., 82: 3701-3704.

16. Agnello, V. and F.G. De Rosa, 2004. Extrahepatic disease manifestations of $\mathrm{HCV}$ infection: some current issues. J. Hepatol., 40: 341-352. 